\title{
Teaching Challenges and Perceptions on STEM Implementation for Schools in Saudi Arabia
}

\author{
Rehaf Anas Madani 1*
}

\author{
${ }^{1}$ British University in Dubai, Dubai, UNITED ARAB EMIRATES
}

*Corresponding Author: rehafmadani@gmail.com

Citation: Madani, R. A. (2020). Teaching Challenges and Perceptions on STEM Implementation for Schools in Saudi Arabia. European Journal of STEM Education, 5(1), 03. https://doi.org/10.20897/ejsteme/8468

Published: August 8, 2020

\begin{abstract}
STEM education has become one of the most rapidly growing sectors in educational reform all over the world. Whilst the program has been successfully implemented in most countries, unfortunately it has not been introduced as successfully in Saudi Arabia on account of lack of clarity of the general description of the meaning of STEM and its purpose and framework of application. In 2009, the Ministry of Education (MOE) introduced a new mathematics and science curriculum, in collaboration with Obeikan Research Development Company, as an adapted series of science and mathematics textbooks produced by an American publishing company McGraw Hill. The adapted curricula attempt to make meaningful connection between student's lives and their educational experiences through the implementation of new teaching practices which include student-centred investigation strategies and problem-based learning.

The study was limited to Jeddah, Saudi Arabia and used the interviews of high school mathematics and science teachers and class observational methods as a means of qualitative research in order to address the following research questions:

- What are the major aspects of the new mathematics and science curricula that serve as a means of the implementation of STEM education in Saudi Arabia?

- What are the perceptions of teachers on the implementation of the newly adapted science and mathematics curricula?

- How are the newly adapted mathematics and science curricula delivered in the classrooms as form of STEM education?

Results revealed that even though there is haziness in mathematics and science teachers on the actual meaning of the concept of STEM education and its practice, the new teaching strategies that are required by the MOE for the successful implementation of the adjusted curricula, were found to be equivalent to teaching practices that have been proven effective in the implementation of STEM education.
\end{abstract}

Keywords: STEM, MOE, qualitative analysis, curriculum

\section{INTRODUCTION}

Scientific advancements of the $21^{\text {st }}$ century have impacted every aspect of an individual's social life. Requirement of rapidly changing economies are fulfilled via providing quality education in the fields of Science, Technology, Engineering, and Mathematics (STEM education) and it is considered as a top priority (Asunda, 2011; English and King, 2015; Kelley and Knowles, 2016). 
STEM's instructional models are now considered as one of the most emergent areas in the context of education in both developed and developing countries (UNESCO, 2010). STEM education has also been recognized as a way of strengthening mathematics and science curricula. Despite the global and recognition of the benefits of STEM in the educational sector, its application and instructional practices have remained limited (Czajka and McConnell, 2016; English, 2016; Tofel-Grehl and Callahan, 2016). For instance, generally, science education sometimes is unable to encourage and polish the critical thinking abilities of students. Besides, it follows a lecturebased mode of instructions which particularly focuses on the reception of facts in complete dissociation with context and meaning. However, these limitations are overcome by the problem-solving techniques which are not only practiced but also given ultimate value in the STEM education (Trueman, 2013).

In Saudi Arabia, education is now viewed as a key factor for financial and social growth and science and mathematics education have garnered unprecedented common interest (Almazroa, 2013). The new mathematics and science curricula in Saudi Arabia are an adapted version of the curricula, published by McGraw Hill (Obikan for Research and Development, 2010). For instance, curriculum of mathematics is based on adjusted learning which depends on vertical reliance among the educational module and it is built up to create psychological understanding and scientific abilities in children. In particular, this approach relies on inspecting ideas and building subjective aptitudes, and scientific abilities and methods to enhance them.

Science curricula, on the other hand, are centred on writing-based activities with an aim to place students in the centre of the learning and instructing process. Different exercises are designed for recursive learning with an aim to develop and maintain students' interest at all levels. The general theory of science course books underscores the significance of the logic-based examination and reasoning aptitudes (e.g., logical perusing and composing, drawing and gathering tests), and applying scientific information in everyday life (e.g., relating science to other fields of study and society which is considered as an aspect of the implementation of STEM education). In higher grades, science textbooks incorporate subjects such as life processes, cellular structure and heredity. The human body and its systems, movement and relationship with other living beings are basic divisions of science (Mullis et al., 2016).

In the adapted mathematics and science curricula, prioritizing student-centred learning and understanding the concepts instead of relying on memorizing texts follow a constructivist theory. Various theories of progress have been put forward to justify the complex relationship and factors that contribute to changes in the mode of instruction. Some theories stretched the significance of changing the perception of instructors as a major aspect, which in turn prompts changes in instructional practices and the enhancements of students' educational outcomes (Czajka and McConnell, 2016).

In Saudi Arabia, the educational system follows a hierarchical structure that basically comprises of high authorities in the Ministry of Education and lower authorities in schools. Mathematics and science curricula, in the context of this study, is set with relevant material obtained from the Ministry of Education and teachers neither have any role in curriculum development nor the authority to alter or change any topic or subject (Al-Sulaimani, 2010). Alyami (2014) has argued that reform proposals and development projects essentially require the acceptance of the affected division as in educational sector, perceptions of teachers and students greatly influence the success of curricular reforms and development. Policy makers generally believe that changes are brought about by changing the structure; however, in reality, changes can only be made by changing the subjects involved within the procedure. Therefore, the successful outcome of reform measures in educational sector is compromised unless they are formulated and clarified via debate and participatory democratic processes.

The purpose of this study is to determine and comprehend the level of preparedness and inclination of teachers with respect to the implementation of the new mathematics and science curriculum in Saudi Arabia as an advancing step towards the implementation of STEM education. Since this is a new study in this domain, it is important to understand teachers' views and perceptions about the new curriculum and how it will affect their teaching strategies.

Primarily, the focus of this study is to encourage teachers to move away from traditional teaching methods that include lectures and to embrace project-driven methods to project problem- centred learning that establishes a more beneficial learning forum for STEM subjects. As a common practice, in Saudi Arabia, science and mathematics are taught as separate subjects with little or no relevance to real life situations. Therefore, in order to redefine their modes of instruction in the classroom and subscribe to the combined model of STEM education, teachers need to acquire the understanding of what exactly they know about its implementation and integration in the curriculum and how it will improve their teaching experience. 


\section{LITERATURE REVIEW}

\section{Theoretical Framework}

The development of STEM education approach is based on four different pillars: Science, Technology, Engineering and Mathematics. The approach was further defined as the development of a discipline on the basis of the integration of other disciplinary knowledge into a new whole (Sanders, 2009). This integration of different subjects into a single whole was meant to equip students with the ability to deal with the growing challenges.

Since the early 90s, the concept of STEM education has occupied the interest of policy makers and educators. Since then, the integration of STEM into curriculum has been a part of many curriculum reforms such as the Next Generation Science Standards (NGSS) (NGSS Lead States, 2013).

Most of the changes implemented by the STEM education involved the amalgamation of four different subjects to develop both theoretical and practical skills in students. According to the study of Kloser (2014) the implementation of STEM education has mainly emphasized on the change in teaching practices and caused the emergence of a shift particularly in teaching methodology. The approach further promotes practice-based teaching philosophy which bounds teachers to apply useful knowledge, skills and values to develop a strong student engagement. Another feature of the STEM education is that it promotes a curriculum consisting of integrated content of all four subjects including Science, Technology, Engineering and Maths. These curricula are based on very specific objectives which aim to develop the target skills in students (Alhomairi, 2018).

\section{Empirical Review}

According to a study, Meaningful connections formed between prior and current knowledge and between disciplines can help establish schemas which help in the development of cognitive skills and results in deeper understanding in contrast with surface learning (Beane, 1996). To this effect, STEM education could be seen as "a means that supports a constructivist approach in learning as teachers facilitate and scaffold students' meaningful learning" (Becker and Park, 2011).

The success of the implementation of STEM education is dependent on the perceptions and preparedness of teachers. They need to have adequate prior training and understanding in order to teach the new curriculum to students. However, teachers' perceptions and beliefs that shape their approaches and methodologies for the implementation of curricular reform are usually neglected. These concerns were presented in many researches regarding education in Saudi Arabia (Bin-Salamah, 2001). In order to make such implementations, it is important to identify how mathematics and science teachers perceive the shift from traditional teaching strategies to an advanced "incorporated" STEM training-learning model.

Kennedy and Odell (2014) in their study identified different elements for the successful implementation of high-quality STEM education and curriculum. First element is the rigorous instructions for science and mathematics curricula. Second element is the integration of engineering and technology into mathematics and science curricula. Third element is the encouragement of teachers to promote the trend of asking questions, while conducting the investigations. Fourth element is the provision of opportunities for STEM educators and learners with the increased workforce. Mihelich et al. (2016) on the other hand provided insights regarding the importance of developing student learning in different social scientific studies. Findings of the study emphasized on parents' inclination in developing students' interest and attitudes towards science. The study further emphasized on the inclusion of STEM in the education curriculum of K-12 students.

Zeidler (2016) focused on the socio-cultural and socio-scientific perspective of STEM education. Whereas, ElDeghaidy and Mansour (2015) examined the perceptions of Saudi science teachers regarding the STEM education and its multidisciplinary nature. Findings of the study indicated a need to develop a professional model to analyse the lacking of the science teachers in terms of the pedagogical content that would promote the enactment of STEM education in classes. A similar study was conducted by Madani (2017) which investigated the teacher's perception and instructional practices with respect to the science and mathematics curricula as a positive step towards the implementation of STEM education in the educational system of Saudi Arabia. Findings of the study indicated certain level of haziness regarding the concept of STEM education in the educational curricula. Besides, the new teaching strategies implemented by the Saudi Ministry of Education were found equivalent and effective in the implementation of STEM education.

Aldahmash et al. (2019) conducted another study to analyse the attitudes of Saudi Arabian mathematics and science teachers towards the integration of STEM education in the science and mathematics curricula of middle school. Findings of the study supported the integration of professional development programs which ultimately resulted in decreasing teacher's difficulties regarding the implementation of STEM. Also, a significant improvement in teacher's self-efficiency was identified due to their participation. Williams et al. (2015), on the other hand, highlighted the instructional preferences of teachers who belonged to the system of STEM education. 
Findings of the study identified in-class instructions including group work and problem-solving strategies. Besides, most of the teachers preferred summative assessment practices.

Henderson and Dancy (2011) identified the role of individual educational professionals, as they primarily serve as the policy and curriculum developers and tend to create new instructional strategies through educational research, which are then implemented to obtain practical results. Such techniques, in most cases, fail to consider the unique identities of students, teachers and schools in every region. In some cases, these strategies often lead to academic success and provide expected results, while in other cases, undesired outcomes are obtained.

The evidence of teachers' self-efficiency should also be needed. "For teachers to be able to teach integrated STEM, they need professional development experiences, adequate planning periods and adequate content preparation" (Harrell 2010). This study aims to provide evidence that teachers are not adequately supported with the infrastructure and means required to successfully implement the curriculum. The STEM school culture requires "collaboration amongst stakeholders as well as establishment of a collaborative and supportive STEM education community (Basham, Israel, and Maynard, 2010). Teachers are required to have a comprehensive understanding of STEM education and they should be adequately equipped to handle the transition from lecture- centred mode of instruction to student-centred one.

\section{METHODOLOGY}

The methodology provides a descriptive analysis through the use of different forms of qualitative measures such as interviews and observational methods (Ary, Jacobs, Sorensen, and Walker, 2013). The study is specifically conducted in Jeddah, Saudi Arabia, in order to address the following research questions:

- What are the major aspects of the new mathematics and science curricula that serves as a means of the implementation of STEM education in Saudi Arabia?

- What are the perceptions of teachers on the implementation of the newly adapted science and mathematics curricula?

- How are the newly adapted mathematics and science curricula delivered in the classrooms as means of STEM education?

The purpose behind using basic interpretative research was to understand how high school mathematics and science teachers perceive events, processes and activities, while practicing the new mathematics and science curricula in the classroom in a bid to implement STEM education in Saudi Arabia.

The research study focused on using personal open-ended interviews with participating teachers to gain a deeper understanding of the major aspects of the new mathematics and science curricula and class observational methods were applied to comprehend how the new required teaching methodologies are practised in the classroom.

\section{Sampling}

\section{Target population}

The context of this research study is centred on the Kingdom of Saudi Arabia (KSA). However, depending on a homogeneous sampling, the researcher selected similar cases to describe a subgroup in depth rather than all members of the population (Glesne, 2011). It was also used to ensure that the data obtained was related to the scope of the research understudy (Onwuegbuzie and Collins, 2007; Fraenkel et al., 2015). Sampling was limited to Jeddah; the selection of this area was based on the researcher's ease in accessibility to potential study participants and information.

Selection of science and mathematics teachers teaching the new mathematics and science curricula to the higher grades (grades $11 \& 12$ ) was made. The teachers were assigned by the participating schools on the basis of their qualifications, willingness to take part in the study and most importantly their experience in teaching both the previous and the new mathematics and science curricula in Saudi Arabia.

Eight high school teachers participated in the study; four of whom were selected for the semi-structured interviews and the remaining four for the classroom observational methods. The entire procedure was carried out to gain deeper and wider perspectives of research objectives from different angles and to gain a clear picture of teachers' perceptions of the new mathematics and science curricula with respect to its implementation practices in the classrooms and. The participants were selected from four schools: one school was only for boys and the other three were only for girls.

Based on the objective of this study, only four subject teachers teaching mathematics, biology, chemistry and physics were interviewed. These interviews were carried out in order to gain in-depth information and observation 
on each subject to be able to build a convincing analytical narrative which should be based on richness, complexity and detail for each subject.

\section{Data Collection}

\section{Interviews}

Interviews are considered as the most popular form of qualitative methods of research as they provide authentic information of participants' personal experiences and perceptions about a certain matter (Melles, 2005). Interview questions in qualitative studies usually focuses on participants culture, perceptions, experience, understandings, meanings and problems studied, in order to investigate their plans, intentions, roles, behaviour and relationships regarding the understudy research topic (Tuckman and Harper, 2012).

Therefore, interviews are perceived as a powerful tool to gain insight about educational issues by understanding personal experiences of involved individuals and receiving more in-depth responses (Seidman, 2013; Crabtree and Miller, 1999).

The semi-structured instrument consisted of nine open-ended questions designed to investigate mathematics and science teachers' perceptions and classroom practices with regards to the new mathematics and science curricula used as an advancing step towards the implementation of STEM education in Saudi Arabia. The purpose of the instrument was to provide teachers with the opportunity to describe and elaborate the relationship between their perceptions about new mathematics and science curricula and their daily classroom practices.

In order to maintain the quality of an interview, Shensul et al. (1999) suggested three principles: maintain the flow of the interviewer's questioning and participants' responses; sustain a positive relation with the participants and avoid interviewing bias. In this research study, the researcher took the role of the interviewer. Interviews were conducted fairly as all participants were asked the same questions in the similar order. Furthermore, the questions were worded in an open-ended format which allowed participants to contribute in shaping the discussion and feel free to share their perceptions, experiences and attitude regarding the subject (Bogdan and Biklen, 1998).

The duration of each interview ranged between forty-five minutes to an hour, which is an appropriate time for conducting interviews as described by Glesne (2011). Participants were briefed beforehand about the research topic, rationale and objectives and their doubts were also clarified to maximize the successful output of the interviews. The interview questions were first formulated in English and then translated into Arabic: the first language of Saudi Arabia.

In order to ensure the accuracy and validity of the translation and to make sure that the meanings were not lost in translation (Kapborg Bertero, 2002) assistance of two certified translators was taken (Simon, 2011). Appointments with the school principals of the participating schools were taken ahead of time.

Four teachers were interviewed; three of them were female who were teaching mathematics, biology and physics in three different girls' schools in Jeddah, Saudi Arabia. Each interview was held within the school premises and lasted for approximately forty-five to sixty minutes. The fourth interview was conducted with a male high school teacher teaching chemistry. Due to gender segregation policy in Saudi Arabia's schools, the interview was conducted over the phone after getting the school principal's permission.

Methods used for documentation and later analyses included note taking and audio tape recording (DiCiccoBloom and Crabtree, 2006). Participants' consent was obtained prior to the interview regarding the audio recording of the interview. After the completion of data collection process, each interview was carefully listened and noted to eliminate the chances of bias in results. More precisely analysis of data obtained from the observational method was carried out by using Krathwohl's (2009) three main stages. The first stage involved familiarization and organization of the observed facts. The second stage involved coding and recoding of obtained data and finally the third stage involved thorough summarizing and interpreting of the obtained results.

In order to test the trustworthiness of interview questions, a panel of educational experts including educators and teachers were asked to judge the translation, context and validity of the instrument. Three educational experts assisted in reviewing the questions including a science professor from Dubai, a school principle from Jeddah Saudi Arabia, having a 25-year experience of teaching mathematics in Saudi Arabia and a retired Biology teacher with 22 years of teaching experience in Saudi Arabia.

\section{Classroom observations}

Tofel-Grehl and Callahan (2016) described that the best path to understand the implementation of STEM education within STEM schools is via the study of classroom discourse. The main focus of classroom observational methods in this study was to describe whether teachers' perceptions are aligned with the applied teaching practices regarding the implementation of the adapted mathematics and science curricula as an advancing step towards the implementation of STEM education in Saudi Arabia. 
In order to conclude and to effectively answer the research question: "How is the newly adapted mathematics and science curricula delivered in the classrooms as a means of STEM education?", the researcher conducted classroom observational methods within participating schools in Jeddah, Saudi Arabia.

Four schools participated in the qualitative part of the research study as it was described earlier; one school was a boys' school, while the remaining three were girls' schools. In accordance with the gender segregation policy implemented in Saudi Arabia, only three schools were included in the class observational method. It was due to the fact that the researcher was denied access to the boys' schools, on account of being a Saudi female. Moreover, since the research was not under the research panel of Ministry of Education, video tape recordings were also denied. Therefore, class observational methods were limited to the selected girls' schools of Jeddah, Saudi Arabia. Classroom observations of the biology and chemistry teachers were conducted in only one school, while for physics and mathematics, each observation was conducted in a different school.

The primary focus of the classroom observations was to investigate teachers' application of the new instructional practices implemented by the Ministry of Education to teach the new mathematics and science curricula as an advancing step towards the implementation of STEM education. The observations were purposefully conducted during participants' STEM integration lessons by using an observational checklist that was developed by the researcher, which is relevant to the scope of the research topic and the nature of the research questions. The observational checklist included two sections. The first section dealt with the investigation of the applied teaching strategies to answer the following question: "How well did the teacher cover the following teaching approaches in the classroom?" This investigation was done via the observation of the following subdivisions: lesson opening, quality of teaching, mode of instruction, association of taught subjects with students' daily life issues, and developing connections in different STEM subjects when teaching. The second section included the observation of the overall learning environment in the observed mathematics and science classrooms.

In order to ascertain trustworthiness of the instrument, a pilot classroom observation was undertaken with a female mathematics teacher who was teaching students of $12^{\text {th }}$ grade in one of the participating schools in Jeddah, Saudi Arabia. The observational trial assisted the researcher to focus on the required observational techniques and note taking with respect to the scope of the research topic. The trial helped in clustering the observational checklist. Some of the columns were deleted and more emphasis was given on observing the subject integration between the topic taught and STEM subjects.

In order to eliminate bias, the researcher took the position of a silent uninvolved member during all classroom observational methods, as no interaction was made with the teacher or any of the students during the classes. The researcher was observing the classes silently, not pass judgement on the settings as everything was recorded as it occurred. Further, the researcher adapted the two-column field note taking strategy (Hammer, Prel, and Blettner, 2009).

In the observational checklist, the researcher used two columns for taking classroom notes: one column to report the indicators for teacher-student interactions, while the other column was used for writing personal thoughts and comments, which separates the observer's personal comments and thoughts from the actual observations.

The classroom observational method was applied to investigate all the activities and interactions between participating teachers and their students to monitor their interactions with the activity (Merriam, 2009). As the format of the lesson plans varied significantly among teachers teaching different STEM subjects (mathematics, physics, chemistry and biology), the number of classroom observations was also varied depending on the coverage of each STEM subject and chapter, each class was 45 minutes long. In chemistry, a total of six classes of the same teacher of grade 11 and 12 were observed.

Topics covered during the six classes included the ionic and covalent bond which was covered in two classes; alkaline battery topic was covered in two classes and the hybridization chapter was also completed in two classes. In biology, a total of five classes of the same teacher of grade 11 and 12 were observed. Topics covered during the five classes included bird anatomy which was completed in two classes including one conducted in the science laboratory and the circulatory system which was covered in three classes. In physics, three classes of the same teacher of 11 and 12 grade were observed. Topics covered during the three classes included the Quantum theory, Kinetic energy and Newton's first law. In mathematics, five classes of the same teacher of grade 11 and 12 were observed. Topics covered during the five classes included Pascal theory, binomial theory, polar coordination, resume limits and tangent and velocity. The reason behind choosing to observe more than one chapter in each subject was to ensure that the researcher gathered enough evidence for the comprehensive analysis and investigation of the applied instructional practices. 


\section{RESULTS}

\section{Teachers Interviews}

\section{Q1) Are you familiar with the concept "STEM education", if yes please describe it for me?}

Not all interviewed teachers heard the term 'STEM'; however, description of the meaning of the term revealed that three participants were familiar with it. The physics teacher was the most familiar with the theory of STEM education as she was able to give a complete definition of its implementation, purpose and objectives. Further, the teacher described that finding relevance between different STEM subjects when teaching and relating given topics to students' lives is a requirement of the new curricular implemented by the Ministry of Education.

Q2) Do you believe that the new mathematics and science curricula is a step forward in Saudi Arabia's educational reform and a step towards STEM implementation? Explain.

In this question, all participants shared positive views regarding the new mathematics and science curricula as being a sign of educational improvement in Saudi Arabia. Moreover, they all agreed to the existing challenges lying ahead in the implementation of the new curricula to accomplish the objectives and academic success. The physics teacher explained "The new curricula are more advanced in terms of the information included and the level of coordination among subjects including the sequence of its topics. Since education in the Arab world was initially introduced, teachers were viewed as a sole source of knowledge and information. However, in present times, their roles bave transformed to facilitators, as students are now more indulged in their own learning. To me, this is a major aspect when it comes to STEM implementation, I cannot say that the new curriculum is fully meeting its objectives yet, but with time and more training I'm sure it will'. The teacher further described, "When the given topic is related to a real-life scenario, students become more interested and feel the connection with the topic, which makes it difficult for them to forget or neglect new information, especially if it is related to their life or health circumstances. STEM implementation is not yet considered as a requirement from the Ministry of Education, connections between different STEM subjects are applied as an extra effort from the teachers".

The new curriculum is a form of STEM education though a lot of teachers and students might not have noticed it yet. Additional focus is required for the implementation of STEM education and subject integration in specific and on the whole learning and teaching experience in general.

Q3) Do you have the experience in teaching the old curricula? If your answer is yes, did you experience differences in your coursework and instructional approaches required for the implementation of the new curricula when compared with the old one?

The teachers that were interviewed were able to identify differences between the old and new curricula. The biology teacher noted "The new curriculum is better, as there are stated objectives at the start of each chapter, which could be used as a framework for lessons. However, some topics required more evaluation before presenting lessons to students". The physics teacher on the other hand described, "As teachers we are challenged not only in our ability to carry a class using new active learning, student-centered teaching techniques, but are also to be informed about other STEM subjects as well. Moreover, the new curricula add excess load on teachers when compared with the old one, as it requires teacher's knowledge and experience to read information that are found between the lines and be able to clarify them to students. Implementing new instructional practices including student-centered teaching techniques requires not only teacbing experience, but also more time in class". The mathematics teacher on the other hand, explained, "The new mathematics curricula is stronger in content, as it focuses more on the basics of mathematics through new engaging teaching techniques, that increases students' interest and encourages classroom engagements". The above-mentioned statements sufficiently explain that most of the teachers supported the use of new teaching method. However, one of the major concerns raised by the respondents included that the new approach demands regular updating of the subject knowledge remain in line with the new advancement and development in their respective fields of studies. This further emphasizes the need for frequent development of professional development programs, as suggested in the studies of Aldahmash et al. (2019) and El-Deghaidy and Mansour (2015) respectively.

Q4) In your opinion, in the new curricula does the Ministry of Education aside from connecting mathematics and science subjects to real life scenarios, focus on STEM implementation or subject's integration in their annual visits?

Most mathematics and science teachers indicated that the new curricula focus more on students' engagements and puts more weight on the relevance of subjects to students' daily lives. However, implementation of STEM education and the integration of its subjects are carried out within that process.

The physics teacher explained that the Ministry of Education focuses mainly on the new active learning strategies and new student-centred teaching techniques, according to which teachers are supposed to act as facilitators and help and guide their students to search and get the information by their selves. Additionally, the teacher explained, "Minimum emphasis is concentrated towards the implementation of STEM education or subject integration between physics and other different science subjects". Despite the fact that implementation of STEM education is not a part of the Ministry's direct requirements, it is still required to accomplish the goals and objectives of the new curricula. 
Q5) Are teachers qualified to teach the new mathematics and science curricula? Explain the challenges that faced you as an instructor.

With respect to the issue of teacher's qualifications to teach the new mathematics and science curricula, teachers shared mixed views. The biology teacher stated, "In this school we bave three biology teachers, I believe all of us are qualified and well-informed in teacbing the new biology curricula, in terms of its content and are aware of all new teaching requirements and methods". On the other hand, the physics teacher disagreed, as she described teachers as unqualified in teaching the new physics curricula, highlighting two challenges: the language barrier because most teachers are not familiar with the meaning and pronunciation of most scientific terminologies included in the new curricular textbooks and the challenge of implementing new instructional practices required for teaching the new mathematics and science curricula as teachers tend to revert to their old teaching methods. Further, the teacher added, "When the new mathematics and science curricula was first introduced, it created a huge gap for both the teachers and the students, as it was very challenging for us teachers to build new information with students having no base. "

Q6) As a teacher, were you offered any sort of teachers' development programs or workshops as a preparation to teach and implement the new mathematics and science curricula? How important do you think is it for teachers?

It was concluded from the participant's different answers that teachers were not all required or obliged to get enrolled in workshops or teachers' developing programs before teaching the new mathematics and science curricula. The chemistry teacher stated, "I do not deny the importance of teachers' development programs and workshops; I believe it is the most effective tool to curricular reform success and a window for teachers to learn how to apply new different teaching techniques. Despite that, I have been teaching high-school chemistry for a couple of years now, so far I was not obliged to enrol in any courses or workshops."

This indicates that many teachers, despite knowing and understanding the value of teacher's development programs refrained themselves in getting enrolled in these programs to optimize their productivity. The responses further indicated that most of the teachers, despite their willingness were unable to attend these programs on account of strict work schedule. This pinpoints towards another factor that may support the given argument that teachers are unable to manage time for attending such purposeful events due to their workload.

Q7) What do you think are the major aspects of the new mathematics and science curricula, that are considered as a step towards implementing STEM education in Saudi Arabia?

The mathematics teacher highlighted the fact that mathematics, unlike other science subjects, is considered as rigid and difficult, which makes it very challenging for the teacher to engage students in the entire learning process. Nevertheless, the new curricula aim to raise the interest of students by challenging them to solve mathematical problems that are related to real life scenarios. Furthermore, numerous exercises given at the end of each chapter are considered as an excellent addition to the mathematics textbooks. The exercises highly vary in their level and style, which helps students practice beyond the confines of their books and consequently become more familiarized with international exam questions.

The physics teacher indicated several aspects of the new physics curricula that were not the part of the old one including summary at the end of each chapter to help students review and reorganize the chapter's points and build up on this information. The new curriculum is more research oriented and relevant to students' real-life situations and circumstances. The biology teacher pointed out three characteristics of the new science curricula which verified that educational reformation in Saudi Arabia is on the right track. Most of the teachers observed that the new methods were sufficient in developing critical thinking skills in students as well as increased classroom interaction and response. From these responses, it can be safely concluded that the new methods are sufficient in directing students towards the development of required skills.

Q8) What is your overall conclusion on the newly implemented mathematics and science curricula?

Despite the fact that most participants shared mixed views and feelings regarding the new mathematics and science curricula, they were all optimistic that this educational reformation is a positive step towards the improvement in Saudi Arabia's educational system in general, and students' output in STEM subjects in specific.

Most of the teachers identified high improvements in students' understanding of the basic concepts. Further improvements were also observed in the methods of assessments conducted by teachers with respect to the student's performances.

\section{Q9) Do you have any additional comments that you would like to share?}

The mathematics teacher explained, "Improving the overall process of learning does not depend solely on coming up with new curricula. In order to improve our educational standards, schools must rely on outside exams that are given from someone other than the teacher who is teaching the topic, so both the teacher and the students can be encouraged to put more effort to improve. I believe that there will be no improvements in education as long as the teachers do not improve, also, there are too many holidays during the semester, which carries a negative effect on students learning". She added "The down side is that the Ministry of Education does not consider STEM as part of the new curricula's major requisites". 
The above statement therefore emphasizes on the fact that the existing measures of the government are insufficient regarding the inclusion of STEM education in the current educational system. This identifies the gap found in the strategies planned by the government which are insufficient to fulfil the academic needs of both students and teachers.

\section{Classroom Observational Results}

Observation of instructors' teaching practices in classrooms plays a significant role in enhancing students learning in different disciplines of STEM education (Smith et al., 2013). In this section, the researcher relied on an open-ended observational protocol in which the researcher attended classes, took notes and commented on students' involvements and interaction within the classroom by using a formulated observational checklist.

Within each observational section, results were further classified into two parts: the first part was the observation of science classes including physics, biology and chemistry and the second part was the observation of mathematics class. Analysis of the data obtained from observational method was carried out using Krathwohl's (2009) three main stages. The first stage involved familiarization and organization of observed facts. The second involved coding and recoding of obtained data and the third stage involved summarizing and interpreting of the results. At the end, a table was created to summarize the points between different subjects observed via the class observational checklist.

Through observations it was found that all the four teachers opened their lessons through a brief discussion about the topic and its relevant background. Besides, the quality of teaching was determined on the inclusion of student-centred teaching strategies which ultimately supported quality teaching. Mathematics teachers incorporated different short classroom activities to enhance students' skills and science teachers incorporated further instructional activities which ultimately increased students' response in classroom discussions. Students' participation further increased with the inclusion of different short exercises meant to develop a connection between scientific facts and real-life situations.

\section{DISCUSSION}

Results were analysed to investigate teachers' perceptions and instructional practices of the new mathematics and science curricula as an advancing step towards bring about educational reforms in the Kingdom of Saudi Arabia. The objective was to gain an insight of how teachers perceive, acknowledge and implement the new teaching practices required for teaching the new curricula, and its relevance with instructional practices required for the implementation of STEM education. Findings were presented with an aim to generate a base for further research to improve the standards of Saudi Arabia's educational system in general and the abilities of students in the fields of mathematics and science in specific.

The fact that STEM education is not a familiar term among most individual participants of this research, thi study determines fact that there is a general haziness regarding the terminology and meaning of STEM education. A successful integration of mathematics and science subjects mainly depends on teachers' academic competence with respect to subject knowledge and the integration processes. There are many challenges in the implementation of STEM education; one of the main challenges is the need of a clear definition of the acronym STEM in STEM education (Brown et al., 2011). Moreover, many teachers face some difficulties in teaching their own subjects when they are asked to integrate other subjects as this could be challenging and may lead to miscommunication. This confusion affects the delivery of information by the teacher and its reception by the students (Stinson et al., 2009). Notwithstanding the many possible benefits STEM education provides, it is vital to concentrate on teachers' understandings, practices, efficiency and strategies required for a successful implementation of integrated STEM education (Stohlmann et al., 2012).

The results indicated that when teachers were asked about their familiarity with STEM concept, three out of the four teachers responded by using the "yes" word as an answer but only one of them was able to further explain the meaning of STEM. Further, participants' responses were also found to be consistent in classroom observational results which indicated that the focus was more towards the application of new teaching methods than the integration between subjects.

Several ways were highlighted for getting acquaintance with STEM education including subject integration within different disciplines of STEM education, the application of new teaching practices, relevance of the new curricula and the encouragement of students' involvement. These points were related to the interview responses regarding the application of new instructional practices as demanded from the Ministry of Education. Moreover, they were relevant with the observational data obtained by observing different mathematics and science classes. These findings are in line with those provided in the study of Madani and Forawi (2019), according to which the new curricula implemented by the Saudi Ministry of Education were effective in developing meaningful 
connections between student's real life and educational experiences. This further involved the inclusion of new teaching strategies. Aldahmash et al. (2019) endorsed the results of this study and indicated that most of the implementation of STEM education was instrumental in improving students learning efficiency. It was also instrumental in increasing teachers' self-efficiency by the adoption of different teaching approaches. Results of this study further indicated that some teachers were unable to identify the appropriate meaning of STEM education, which showed unpreparedness with respect to the criteria of STEM education. These results were also in line with those presented in the study of El-Deghaidy et al. (2017), according to which most of Saudi science school teachers reflected lack of preparedness regarding the implementation of STEM education practices. However, recommendations regarding the provision of teacher's development programs were provided to improve the education level of both teachers and students.

Respondents described several points which they considered as interior and exterior barriers that challenged the implementation of new teaching strategies and subsequently, the implementation of STEM education. These barriers included poor instructional design, rigid school structures, isolated subjects and topics, insufficient teacher preparation programs and workshops, time constraints, resistance of teachers and students to accept change, lack of recognition of teachers and students, lack of encouragements, insufficient school resources, large class size and the lack of a unified assessment form.

Ramli et al. (2017) conducted a similar study to identify the challenges faced by teachers in the implementation of STEM education. Findings of the study outlined some important challenges that are in contrast with those postulated in this study. According to the study, most of the teachers faced issues such as lack of confidence, lack of related teaching materials and lack of teaching expertise required to implement STEM education.

Most of the shared themes focused around the idea that the new curricula is more suitable for the next generation with respect to both its material contents and applied teaching strategies. Analysis of teachers' responses revealed that all respondents favoured the new mathematics and science curricula on account of the following factors: its relevance to real life situations, concentration on the development of students' self-efficiency, confidence and motivation and most importantly educational outcomes. Therefore, from the above discussion it can be concluded that the implementation of STEM education is instrumental in supporting the advanced educational standards. However, there has been lack of training sessions and workshops for teachers' professional development which are mandatory to fill the gaps in the successful implementation of STEM education.

\section{CONCLUSION}

The study sought to address a shortfall in the educational system in Saudi Arabia. It sought to examine the perceptions of teachers towards the implementation of STEM education and the interdisciplinary curriculum. An important result of the study revealed the need to enhance dialogue between teachers of different STEM education subjects in order to provide cohesion and promotion of the new curriculum at schools. The idea aims to establish a STEM culture and create a dialogue to enhance partnerships with all key role players. Stoll and Fink (1996) list collegiality as one the features of a positive school culture which includes shared goals and responsibility for success, continuous improvement, lifelong learning, risk-taking, support, mutual respect, openness and humour. Findings further revealed that teachers are not adequately prepared or educated with regards to the implementation of STEM in schools.

Teachers also voiced their concern in the interviews regarding common internal and external issues such as the lack of adequate facilities and infrastructure required to support the implementation of STEM education. There were also issues related to the insufficient resources, confusion about examinations, insufficient time to focus on STEM activities, lack of necessary teaching materials and large class sizes which impacted on teaching time. It was evident that teachers were facing difficulties to fully embrace and implement the STEM curriculum. Teachers expressed concern that workshops that were intended to prepare them for the implementation of STEM education could not provide them the necessary tools required for implementing STEM.

It was concluded that in order to comprehensively understand all the elements of STEM education and its integration and implementation, teachers need to be involved in open discussions and intensive collaboration and partnership.

\section{LIMITATIONS}

When conducting a research study, limitations affect the degree of trustworthiness of the research and generalization of its obtained results (Creswell, 2013). The following are some of the limitations that need to be taken into account as they might have had an effect on the findings of the research. 
First, this study is limited by the validity of measurement held by the applied instruments, including semistructured and open-ended interviews of teachers and class observational methods. In the second place, the study was limited to Jeddah and the study sample comprised only eight teachers. Further, participants were only postsecondary mathematics and science teachers who had experience in teaching both the old and the newly adapted mathematics and science curricula in Saudi Arabia. Therefore, results of the findings may not be applicable to new teachers who have prior experience of only teaching the old curricula or to teachers outside the domain of higher secondary education. In the third place, the proposed conceptual framework does not address all the problems concerning the new science and mathematics curricula and educational program such as those imposed by law, by the politics or by teachers' professional development programs. Further on account of the uniqueness of the research topic, at present, there is no protocol purposefully designed to observe STEM integration classes or structured interviews for STEM implementation. Therefore, qualitative instruments applied were developed by the researcher with consideration of the scope of the research study as well as social and cultural concerns. Another important limitation was that the classroom observational methods were implemented only in girls' schools since on account of cultural and religious restriction in Saudi Arabia, schools are gender segregated and the researcher, being a female, couldn't gain access to the science or mathematics classrooms of boys' schools and also videotape recordings were not permitted for classroom observational methods. Finally, much of the research study's literature review was based on research studies conducted in western countries due to the fact that STEM education is considered as a relatively new domain in the educational system with very limited available research especially in the Middle East other Arab countries.

\section{RECOMMENDATIONS}

The outcomes of the research highlighted the need to improve the practical implementation of STEM education in the schools of Saudi Arabia. The results have shown extensive and strong evidence that these results would assist in comprehending the major role that teachers play in the implementation of educational reforms.

The results further provided a window to evaluate the applied teaching strategies and identify the weak spots that should be addressed to provide future support and assistance in the implementation of the new curricula. Recommendations related to research identify several fields of action to improve the impact and diffusion of the STEM education in Saudi Arabia. On account of the lack of supporting studies available in Saudi Arabia, more research is recommended to provide conclusive vision of the new mathematics and science curricular reform. A call for more regional research is necessary to improve scientific educational systems to keep up with the muchneeded rapid speed of development as Saudi Arabia is considered far behind. This exploration study ought to be conducted with a larger sample to affirm its discoveries, where additionally investigations should be done in other geographic areas and crosswise over other STEM orders to recognize whether the techniques distinguished in this review are like those discovered somewhere else. Furthermore, it has been observed that there is very little research regarding the coherence between mathematics and science subjects in the given curriculum and more research is required to investigate how curricular coherence works for students.

Research works should also be carried out on how students perceive and observe these connections. Additionally, the introduction of Reformed Education approaches and its teaching methods should be the focus of teacher's development programs and workshops. Reformed education deals with recruiting and adequately preparing teachers with both the subject knowledge as well as the pedagogical knowledge which is necessary to implement specific teaching strategies needed to effectively teach their subjects. Additionally, inadequate understanding about inquiry-based instruction, complexity of the approach and educational significance to future educators and STEM professionals provide justification to offer and investigate inquiry-based STEM professional development. This development would be useful for faculty members teaching mathematics and science subjects in all school levels.

Regarding practice, additional investments by the authorities in optimizing interaction and collaboration between mathematics and science teachers are required. It could be in the form of establishment of an educational platform that brings together curricular developers, trainers, and teachers to provide resources and reference sources for the formulation of best practice regarding STEM reform in the kingdom. Furthermore, research is required to study redesigning and the restructuring of teachers' development programs and workshops with the addition of STEM training and its implementation practices. Moreover, the enhancement of mathematics and science teachers' participation in workshops and professional development programs especially those that prepare teachers to design and implement integrative STEM education and improved instructional practices. Furthermore, coordination within teachers of different STEM disciplines, should be enhanced and encouraged in order to accomplish successful implementation of STEM education.

For the recommendations related to the field of education, findings have suggested that more effort to increase public awareness on STEM education and strategies are needed for promoting its adoption and implementation. 
In order to implement STEM education in Saudi Arabia, additional focus in organizing and developing correlation between topics within individual STEM subjects are required. Reorganization of the new mathematics and science curricula should be carried out in a way that the topics of different STEM subjects are in sequence and consistent with each other. Furthermore, the development of professional development programs and workshops need to be restructured in accordance with the educational needs, standards and should be as beneficial as possible to match the objective and purpose of the new mathematics and science curricula.

Also, in order to ensure maximum participation of teachers in faculty development and teaching related endeavours, educational institutions as the Ministry of Education and school heads should value such efforts. This can be achieved by motivating faculty members that additional time they spend on developing new instructional strategies will be taken into account in annual reviews, pay revisions, promotions, etc. There is also a need to develop a unified documented tool to investigate instructional practices being carried out in the classroom as a means of assessment and quality control.

\section{REFERENCES}

Aldahmash, A. H., Alamri, N. M., Aljallal, M. A. and Bevins, S. (2019). Saudi Arabian science and mathematics teachers' attitudes toward integrating STEM in teaching before and after participating in a professional development program. Cogent Education, 6(1), 1580852. https://doi.org/10.1080/2331186X.2019.1580852

Alhomairi, A. O. A. (2018). A Proposed Perspective for Developing Science Curriculum for the Upper Primary Grades in Accordance to Saudi Arabia's Vision for 2030: An Analytical and Descriptive Study According to Delphi Method. International Journal of Higher Education, 7(1), 69-86. https://doi.org/10.5430/ijhe.v7n1p69

Almazroa, H., 2013. Professional development: A vision for Saudi science teachers. Esera.org.

Al-Sulaimani, A. A. (2010). The importance of teachers in integrating ICT into science teaching in intermediate schools in Saudi Arabia: A mixed methods study (Ed.D Dissertation), RMIT University.

Alyami, R. (2014). Educational reform in the kingdom of Saudi Arabia: Tatweer schools as a unit of development. Literacy Information and Computer Education Journal (LICEJ), 5(2), 1424-1442. https://doi.org/10.20533/licej.2040.2589.2014.0202

Ary, D., Jacobs, L., Sorensen, C. and Walker, D. (2013). Introduction to research in education. New York: Cengage Learning.

Asunda, P. (2011). Open courseware and STEM initiatives in career and technical education. Journal of STEM Teacher Education, 48(2), 6-37. https://doi.org/10.30707/JSTE48.2Asunda

Basham, D, Israel, M. and Maynard, K. (2010). An Ecological Model of STEM Education: Operationalizing STEM for All. Journal of Special Education Technology, 25(3), 9-19. https:// doi.org/10.1177/016264341002500303

Beane, J. (1996). On the Shoulders of Giants! The Case for Curriculum Integration. Middle School Journal, 28(1), 611. https://doi.org/10.1080/00940771.1996.11496182

Becker, K. and Park, K. (2011). Integrative approaches among Science, Technology, Engineering, and Mathematics (STEM) subjects on students' learning: A Meta-analysis. Journal of STEM Education: Innovations and Research, 12(5), 23-37.

Bin Salamah, M. (2001). An investigation of the relationship between Saudi teachers' curriculum perspectives and their preference of curriculum development models (Ed.D. Dissertation). West Virginia University.

Bogdan, R. and Biklen, S. (1998). Qualitative research in education. Needham Heights, MA: Allyn \& Bacon.

Brown, R., Brown, J., Reardon, K. and Merrill, C. (2011). Understanding STEM: Current perceptions. Technology and Engineering Teacher, 70(6), 5-9.

Crabtree, B. and Miller, W. (1999). Doing qualitative research. 2nd Ed. Thousand Oaks, CA: Sage Publications, Inc.

Creswell, J. (2013). Qualitative inquiry \& research design: Choosing among the five approaches. Thousand Oaks, CA: SAGE Publications.

Czajka, C. and McConnell, D. (2016). Situated Instructional Coaching: A Case Study of Faculty Professional Development. https://doi.org/10.1186/s40594-016-0044-1

DiCicco-Bloom, B. and Crabtree, B. (2006). The qualitative research interview. Medical education, 40(4), 314-321. https://doi.org/10.1111/j.1365-2929.2006.02418.x

El-Deghaidy, H. and Mansour, N. (2015). Science teachers' perceptions of STEM education: Possibilities and challenges. International Journal of Learning and Teaching, 1(1), 51-54. https:// doi.org/10.18178/ijlt.1.1.51-54

El-Deghaidy, H., Mansour, N., Alzaghibi, M. and Alhammad, K. (2017). Context of STEM integration in schools: Views from in-service science teachers. EURASIA Journal of Mathematics Science and Technology Education, 13(6), 2459-2484. https://doi.org/10.12973/eurasia.2017.01235a

English, L. (2016). STEM education K-12: perspectives on integration. International Journal of STEM Education, 3(3), 1-8. https://doi.org/10.1186/s40594-016-0036-1 
English, L. and King, D. (2015). STEM learning through engineering design: fourth-grade students' investigations in aerospace. International Journal of STEM Education, 2(1), 1-18. https:// doi.org/10.1186/s40594-015-0027-7

Fraenkel, J., Wallen, N. and Hyun, H. (2015). How to design and evaluate research in education (9th Ed.). New York: McGraw-Hill education.

Glesne, C. (2011). Becoming qualitative researchers. Boston: Pearson Education.

Hammer, G., du Prel, J. and Blettner, M. (2009). Avoiding bias in observational studies: Part 8 in a series of articles on evaluation of scientific publications. Deutsches Ärzteblatt International, 106(41), 664-668. https://doi.org/10.3238/arztebl.2009.0664

Harrell, P. (2010). Teaching an Integrated Science Curriculum: Linking Teacher Knowledge and Teaching Assisnments. Issues in Teacher Education, 19(1), 145-165.

Henderson, C. and Dancy, M. (2011). Increasing the impact and diffusion of STEM education innovations. In Invited paper for the National Academy of Engineering, Center for the Advancement of Engineering Education Forum, Impact and Diffusion of Transformative Engineering Education Innovations. Available at: http:/ /www.nae.edu/File.aspx

Kapborg, I. and Bertero, C. (2002). Using an interpreter in qualitative interviews: Does it threaten validity? Nursing Inquiry, 9(1), 52-56. https://doi.org/10.1046/j.1440-1800.2002.00127.x

Kelley, T. and Knowles, J., (2016). A conceptual framework for integrated STEM education. International Journal of STEM Education, 3(1), 1-11. https://doi.org/10.1186/s40594-016-0046-z

Kennedy, T. J. and Odell, M. R. L. (2014). Engaging students in STEM education. Science Education International, 25(3), 246-258.

Kloser, M. (2014). Identifying a core set of science teaching practices: A delphi expert panel approach. Journal of Research in Science Teaching, 51(9), 1185-1217. https:// doi.org/10.1002/tea.21171

Krathwohl, D. (2009). Methods of educational and social science research: The logic of methods. Waveland Press.

Madani, R. A. (2017). Teacher Perceptions of the New Mathematics and Science Curriculum: A Step Towards STEM Implementation in Saudi Arabia (Doctoral dissertation), The British University in Dubai (BUiD).

Madani, R. A. and Forawi, S. (2019). Teacher Perceptions of the New Mathematics and Science Curriculum: A Step toward STEM Implementation in Saudi Arabia. Journal of Education and Learning, 8(3), 202-233. https://doi.org/10.5539/jel.v8n3p202

Melles, G. (2005). Beyond the romantic impulse for authentic data to co construction of meaning in interviewbased educational research. Qualitative Research Journal, 5(2), 21.

Merriam, B. (2009). Qualitative research: A guide to design and implementation (2nd Ed.). California: Jossey-Bass.

Mihelich, J. A., Sarathchandra, D., Hormel, L., Storrs, D. A. and Wiest, M. M. (2016). Public understanding of science and K-12 STEM education outcomes: Effects of Idaho parents' orientation toward science on students' attitudes toward science. Bulletin of Science, Technology \& Society, 36(3), 164-178. https:// doi.org/10.1177/0270467616687217

Mullis, I., Martin, M., Goh, S. and Cotter, K. (2016). TIMSS 2015 Encyclopedia: Education Policy and Curriculum in Mathematics and Science. Available at Boston College, TIMSS \& PIRLS International Study Center: http://timssandpirls.bc.edu/timss2015/encyclopedia

NGSS Lead States (2013). Next generation science standards: For states, by states. Washington, DC: National Academies Press.

Obeikan for Research and Development. (2010). Project of mathematics and natural sciences. Available at: http://msdord.com/project.html

Onwuegbuzie, A. \& Collins, K. (2007). A Typology of mixed methods sampling designs in social science research. The Qualitative report, 12(2), 281-316.

Patton, M. (2002). Qualitative research and Evaluation Methods (3 ${ }^{\text {rd }}$ ed.). Thousand Oaks, CA: SAGE Publications.

Ramli, A. A., Ibrahim, N., Surif, J., Bunyamin, M. A. H., Jamaluddin, R. and Abdullah, N. (2017). Teachers' Readiness in Teaching Stem Education. Man In India, 97(13), 343-350.

Sanders, M. (2009). STEM, STEM education, STEM mania. The Technology Teacher, 68(4), 20-26.

Schensul, S., Schensul, J. and LeCompte, M. (1999). Essential Ethnographic Methods: Observations, Interviews, and Questionnaires (vol. 2). Rowman Altamira.

Seidman, I. (2013). Interviewing as qualitative research: A guide for researchers in education and the social sciences. New York: Teachers college press.

Simon, M. (2011). Dissertation and scholarly research: Recipes for success (2011 ed). Seattle, WA: Dissertation Success, LLC.

Smith, M., Jones, F., Gilbert, S. \& Wieman, C. (2013). The classroom observation protocol for undergraduate STEM (COPUS): A new instrument to characterize university STEM classroom practices. CBE Life Sciences Education, 12(4), 618-627. https://doi.org/10.1187/cbe.13-08-0154 
Stinson, K., Harkness, S., Meyer, H. and Stallworth, J. (2009). Mathematics and science integration: Models and characterizations. School Science and Mathematics, 109(3), 153-161. https://doi.org/10.1111/j.19498594.2009.tb17951.x

Stohlmann, M., Moore, T. \& Roehrig, G. (2012). Considerations for teaching Integrated STEM education. Journal of Pre-College Engineering Education Research, 2(1), 27-34. https:/ / doi.org/10.5703/1288284314653

Stoll, L. and Fink, D. (1996). Changing our Schools: Linking School Effectiveness and School improvement. Open University Press.

Tofl-Grehl, C. and Callahan, C. (2016). STEM school discourse patterns. Journal of STEM Education: Innovations and Research, 17(2), 34-41.

Trueman, R. (2013). Productive failure in STEM education. Journal of Educational Technology Systems, 42(3), $199-214$. https://doi.org/10.2190/ET.42.3.b

Tuckman, B. and Harper, B. (2012). Conducting educational research. Maryland: Rowman \& Littlefield Publishers.

UNESCO (2010). Annual Report, UNESCO Office Jakarta. [Online]. Available at: http:/ / unesdoc.unesco.org/images/0019/001921/192108e.pdf

Williams, C., Walter, E., Henderson, C. and Beach, A. (2015). Describing undergraduate STEM teaching practices: a comparison of instructor self-report instruments. International Journal of STEM Education, 2(1), 1-14. https://doi.org/10.1186/s40594-015-0031-y

Zeidler, D. L. (2016). STEM education: A deficit framework for the twenty first century? A sociocultural socioscientific response. Cultural Studies of Science Education, 11(1), 11-26. https://doi.org/10.1007/s11422-0149578-z 